\title{
El nus de la llengua en la xarxa dels sermons vicentins
}

\section{[The knot of the language in the net of Vicentine sermons]}

\author{
Josep E. Rubio \\ Universitat de València
}

orcid.org/0000-0002-0778-3293 // jerubio@uv.es

\begin{abstract}
Resum: Sant Vicent Ferrer empra en ocasions l'analogia de la xarxa per a referir-se a l'estructura del sermó. A partir d'aquesta analogia, podem identificar una sèrie d'elements que es repeteixen en textos diversos i que podem considerar com a nusos de la xarxa. En el present estudi n'analitzarem un de concret: el de la llengua com a identificador del parlant. Estudiarem la rendibilitat d'aquest nus, com apareix en diversos sermons i la manera com enllaça amb altres temes fins a crear una xarxa que va més enllà d'un únic discurs i connecta entre si una multiplicitat de sermons.
\end{abstract}

Paraules Clau: Sant Vicent Ferrer, predicació, semblances, llengua.

Aвstract: Saint Vincent Ferrer sometimes uses the analogy of the net to refer to the structure of the sermon. From this analogy, we can identify a series of elements that are repeated in various texts and which we can consider as knots in the net. In the present study we will analyze one of them: the one of the language as identifier of the speaker. We will study the profitability of this knot, as it appears in several sermons, and the way in which it links up with other issues to create a network that goes beyond a single discourse and connects a multiplicity of sermons to each other.

KeYwords: Saint Vincent Ferrer, Preaching, Similitudes, Language.

Recepció: 26/02/2019. Acceptació: 08/03/2019. Publicació: 05/04/2019

REVISTA VALENCIANA DE FILOLOGIA/I I I (2OI9) p. 389-405/ISSN 055 6-705X/DOI I0.28939/RVF.V3IO.7I 
L'estructura dels sermons del predicador valencià sant Vicent Ferrer segueix uns paràmetres que s'ajusten a allò que proposen les artes praedicandi del moment. La dilatació del tema a partir de la seua divisió en parts és el component fonamental, i més visible, d'aquesta organització estructural del discurs. No obstant això, podem identificar altres elements que articulen el sermó a nivell intern. Així, Josep Antoni Ysern (2017) ha posat de relleu, recentment, la importància del concepte de nus com a element estructurador dels sermons vicentins.

La idea del nus com a peça constituent de primer ordre en el discurs homilètic prové d'una semblança que explica sant Vicent mateix en un sermó hagiogràfic dedicat a sant Pere: el predicador hi explica que el sermó és com una xarxa, feta de diversos filats (tema, cites d'autoritats, semblances, exemples...). Quan un tira de la xarxa, cada filat estira dels altres, perquè tots estan connectats, cosits entre si; llavors la xarxa, o siga, el sermó, arrossega els peixos, que són els pecadors convertits.

Açò dehye Jesucrist per la preycació, que és comparada al filat, que hun fil és lligat ab altre, e quan ve que tiren a ssi lo filat, tot lo filat segueix; axí la preycació deu ésser lligada, $\cdot \mathrm{I} \cdot$ exemple ab altre, una auctoritat $a b$ altra, depuix ab lo fil tire hom lo filat; axí, ab lo tema, tire hom tot lo sermó si bé és ordenat. E en la mar ha molts pexos, grans e pochs; axí en lo sermó pren hom los grans pexos, ço és, quan un hom rich de vosaltres se converteix, que vol restituir los torts, "Oo, hun peix havem pres, hun delfí!»; e, quan en lo sermó se converteix una gran dona, que vol lexar les vanitats, «iOo, una anguila, o una tonyina havem presa!»; e quan en lo sermó se converteix un llaurador, «Oo, un esparrelló havem pres! ¡Oo, una sardineta havem presa!» (Sanchis Sivera 1934: 46-47).

// Aquest estudi s'emmarca en una recerca duta a terme en el marc del projecte finançat pel Ministeri de Ciència, Innovació i Universitats «La cultura literària medieval i moderna en la tradició manuscrita i impresa (VI)», Ref. FFI2017-83960-P (AEI/FEDER, UE). Agraïsc a l'amic i col-lega Josep Antoni Ysern, membre de l'equip de recerca, la lectura de l'esborrany d'aquest article i els seus savis comentaris, dels quals m'he beneficiat. Qualsevol error o mancança, però, han de ser atribuïts exclusivament a l'autor.

REVISTA VALENCIANA DE FILOLOGIA / I I I (20I9) p. 389-405

JOSEP E. RUBIO

El nus de la llengua en la xarxa dels sermons vicentins / 390 
A partir d'aquesta coneguda semblança, que dona títol, a més, a una antologia de sermons traduïts al castellà, amb un interessant estudi introductori sobre les estratègies homilètiques del predicador (Ysern 2015), aquest estudiós proposa l'anàlisi d'aquells components que, com els nusos de la xarxa, són a la intersecció d'aquests fils, donen cohesió al discurs i en sostenen l'estructura interna, més enllà de la divisió tradicional del sermó en parts derivada de la divisió del tema o prosecutio. Aquests nusos serien, en les seues paraules, "grups d'idees més o menys fixats que, com si fossin tòpics preestablerts, poden viatjar entre diversos sermons» (Ysern 2017: 57). És per això que parla de «nusos mòbils» o, tot fent servir una altra semblança, la del sermó com a mosaic, de tessel-les o petites peces, aprofitables per a diversos mosaics.

En un estudi anterior ja havíem entrevist la importància d'identificar una sèrie d'elements reiterats i polivalents, com a peces mòbils que es combinen, que apareixen en diversos sermons i que s'adapten al discurs específic que el predicador vol comunicar en cada cas (Rubio 2007: 137 i 142, n. 15). Ysern, però, amb la idea del nus, en defineix clarament la funció i l'abast i en proposa uns quants exemples clarificadors, de cara al que podria ser un futur catàleg de nusos sermonaris. Per exemple, el nus «baptisme-part», conformat per la idea que el baptisme és un segon naixement espiritual; aquesta idea deriva en una semblança: igual que hi ha un úter físic matern, n'hi ha un d'espiritual (l'Església); igual que hi ha un pare i una mare carnals, n'hi ha d'espirituals. Aquest nus apareixerà en diversos sermons, amb temes diferents, i en contextos també diferents. En un cas, en el sermó de tema «Beati mortui qui in domino moriuntur», sobre l'estat de les ànimes després de la mort, l'aparició d'aquest nus servirà per a explicar l'estat dels infants morts després del baptisme i per a negar una "heretgia» que sembla haver sentit a algunes dones, segons la qual els xiquets morts pateixen pena en el més enllà, encara que hagen estat batejats, per purgar el dolor que han causat a les mares (se suposa que es refereix al dolor del part). En un altre sermó, per contra, de tema «Semen est verbum Dei», el nus serveix com a explicació de les virtuts de la paraula de Déu, la primera de les quals és la paraula com a «semen» en baptismal generació. Finalment, en un sermó de tema «In omnibus honorificetur Deus», en parlar de l'honor i

REVISTA VALENCIANA DE FILOLOGIA / I I I (20I9) p. 389-405 JOSEP E. RUBIO El nus de la llengua en la xarxa dels sermons vicentins / 39I 
la reverència deguda als pares, introdueix la distinció entre "pares carnals» i «pares espirituals» gràcies, de nou, al nus que explica la relació entre baptisme i part (Ysern 2017: 44-47). L'aparició d'aquest nus mòbil, doncs, dona lloc a diversos temes en diversos sermons, però sempre relacionant-los amb la idea central que l'articula.

La nostra intenció en el que segueix és presentar el que podria ser un altre d'aquests nusos: el de la llengua com a instrument comunicatiu i, alhora, com a marca identitària del parlant. Veurem que aquest nus té també una rendibilitat important en alguns sermons, ja que dona peu a connectar el discurs amb temes destacats com la blasfèmia, un dels cavalls de batalla de la reforma dels costums socials promoguts per la predicació vicentina, entre altres qüestions derivades.

La diversitat lingüística era un fet evident al qual s'havia d'enfrontar cara a cara el predicador medieval. Per a sant Vicent, segons diuen els seus hagiògrafs, això no suposava cap problema, ja que era capaç de fer-se entendre per qualsevol auditori predicant sempre en valencià. La realitat devia ser una mica més complexa, i segurament el predicador posava en joc tota una sèrie de recursos comunicatius per a fer-se entendre, entre els quals la gestualitat jugava un paper important, però també l'adaptació al llenguatge del receptor (Ferrando 1997). D'altra banda, hi ha moments en les reportacions que ens han arribat dels seus sermons on manifesta expressament una clara consciència de la pluralitat lingüística, qüestió que aprofita com a nus temàtic del qual extraurà una aplicació moral pràctica, com és habitual en la seua predicació, on tot va a parar, finalment, a una admonició sobre el comportament que ha de tenir l'auditori per a salvar la seua ànima —en definitiva, una admonició a la conversió a la penitència.

Les referències a la llengua poden constituir doncs un d'aquest nusos mòbils dels sermons de sant Vicent. Entenem per llengua tant l'accepció 'llenguatge o conjunt de mots i formes de parlar propi d'una nació' (tercera accepció de l'entrada llengua al DCVB), com l'accepció primera d'òrgan musculós que està situat dins de la boca', i que és també 'l'agent principal de la paraula', seguint el mateix DCVB. En tots aquests sentits empra sant Vicent el terme; normalment, en el nus tal com l'identificarem, llengua significa bé 'idioma', bé 'parla', 'ma-

REVISTA VALENCIANA DE FILOLOGIA / I I I (20I9) p. 389-405 JOSEP E. RUBIO

El nus de la llengua en la xarxa dels sermons vicentins / 392 
nera d'expressar-se amb el llenguatge', 'ús peculiar de la parla' que, en qualsevol cas, identifica l'usuari com a membre d'una nació o d'una comunitat. També, però, aquest nus portarà sovint a referències a la llengua com a l'òrgan de la parla, com veurem tot seguit.

La llengua identifica el parlant no sols com a membre d'una nació, sinó com a membre d'un grup, ja siga social, professional, etc. Hi ha un terme llatí que pot referir-se a la parla com a element identificador: loquela. Apareix en una cita bíblica que pot servir-nos per a donar nom al nus al qual ens referim, ja que sovint — però no sempre- apareix com a text introductori ${ }^{1}$ al nus de la llengua com a element que identifica el parlant: «loquela tua manifestum te facit» (Mt. 26, 73) ('La teua parla et delata, t'identifica, traeix qui eres').

La frase pertany al passatge evangèlic de les tres negacions de sant Pere, quan davant la seua insistència a negar que coneix Jesús, per por de ser detingut ell també, els criats que són amb ell al pati de la casa de Caifàs, el gran sacerdot, el posen en evidència en dir-li que el seu accent el delata com un dels galileus que acompanyaven el de Natzaret. "Loquela tua manifestum te facit» ('la teua parla et delata'). En la versió de la Bíblia Valenciana Interconfessional: «És veritat que tu també ets d'ells: si fins i tot se't nota per l'accent amb què parles!».

El passatge és glossat pels teòlegs de manera que expliquen, en sentit literal, què significa exactament en la història de la narració evangèlica, i alhora en trauen una interpretació moral que seguirà fil per randa el nostre predicador. Primerament, la glossa evangèlica exposa el sentit literal del versicle: sant Pere és descobert perquè parla de manera diferent dels habitants de Jerusalem. Com és possible, si era jueu com ells? És que no parlaven la mateixa llengua? Sant Tomàs d'Aquino ho explica així en el seu Comentari a l'Evangeli de Sant Mateu:

1 Ysern en diu «cotext», que diferencia del «context» d'aparició del nus: «Entenc per context l'explicació resumida de la situació textual que permet l'aparició d'un nus determinat. Pot tractar-se d'un motiu temàtic, com quan l'orador esclareix el sentit del thema triat [...]. Per cotext, tanmateix, entenc els fragments textuals que poden acompanyar, com una mena de marc, algun d'aquests nusos i que, en algun cas, pot ser entès com una mena d'esperó que indueixi l'aparició del nus en qüestió» (Ysern 2017: 58).

REVISTA VALENCIANA DE FILOLOGIA / I I I (20I9) p. 389-405 JOSEP E. RUBIO El nus de la llengua en la xarxa dels sermons vicentins / 393 
Unde dicunt ei et tu ex illis es; et hoc probant nam et loquela tua manifestum te facit. Sed constat quod omnes Iudeai erant; quomodo ergo dicit nam et loquela tua manifestum te facit? Solvit Hieronymus quod in eadem lingua saepe diversa locutio fit, sicut patet in Francia, et Picardia, et Burgundia, et tamen una loquela est. Sic Galilei aliquam differentiam habebant a Ierosolymitanis. (Tomàs d'Aquino 1951: cap. 26, 1. 7).

Fins ací el que seria la interpretació historial o literal del passatge, que coincideix més o menys amb el que podem trobar en nota a peu de pàgina en la traducció valenciana de la Bíblia Interconfessional: «Pere parla amb l'accent propi de l'arameu que es parlava a Galilea, i això el delata» (BVI, NT: 68). Tot seguit, continua amb el sentit moral, segons el qual, i a partir de la connexió d'aquest versicle amb un altre de l'evangeli de Lluc ( «Ex abundantia cordis os loquitur», Lc 6, 45), es poden diferenciar, a partir de la parla, els hòmens carnals dels espirituals: "Sic et cuilibet potest dici: nam et loquela tua manifestum te facit; quia, ut dicitur Lc VI, 45, ex abundantia cordis os loquitur; quia cum homo est carnalis, cito prorrumpit in verba carnalia; cum spiritualis, in verba spiritualia» (Tomàs d'Aquino 1951: cap. 26, 1. 7).

Vegem ara alguns exemples de l'aparició d'aquest tema en els sermons vicentins. El tractament és exactament el de la glossa que hem vist en el comentari de sant Tomàs, per bé que amb modificacions de detall que són adaptacions del predicador a l'auditor. Així, en el sermó de tema «Vos deorsum estis; ego de supernis sum» (Schib 1984: 177-181), sant Vicent dona tres senyals per a conéixer si un és "de paraís o d'infern». Senyals que poden indicar on està predestinada la persona. La primera és «parlament de boca»:

E com? Digau: en què coneix hom una persona de qual terra és? En lo lenguatge, car si vós parlau ab hom estrany, en la lengua conexereu de qual terra és: si parle català, oo, català és; si francés, francés, etc., car la lengua done a conéxer la persona de qual terra és. E açò ja veheu si és clar. (Schib 1984: 178).

REVISTA VALENCIANA DE FILOLOGIA / I I I (20I9) p. 389-405

JOSEP E. RUBIO

El nus de la llengua en la xarxa dels sermons vicentins / 394 
L'explicació de les diferències dialectals entre l'arameu parlat a Galilea o a Jerusalem esdevé ací una diferenciació molt més propera a l'experiència de l'auditori de la predicació, sense alterar per això el sentit de la glossa del passatge evangèlic. El qual, per cert, no és citat encara pel predicador: abans esmentarà una altra autoritat de l'antic testament, del llibre dels Jutges; una història segons la qual una tribu d'Israel en guerra amb una altra identifica els enemics per la forma de dir «espiga de blat»:

Legim que en la terra de Jerusalem eren los tribs de Israel qui havien guerra mortal, que si-s poguessen matar, no s'i trigaven. E veus que la hun trib havie a passar lo flum Jordà. Ordenada la batalla, digueren los altres: «Sabeu com o podem fer que.ls haurem? Anem a lo flum Jordà, e axí com ells se'n tornaran, nosaltres los matarem». «Hoc, mas si no.ls conexerem?» «Sí farem en la lengua, que ells dien "sebolet", e nosaltres "tebolet" (que vol dir 'spiga de trigo')». E axí fon, que quan venien $\mathrm{X}$ o XII, al passar del riu aquell deyen: «D'on veniu? Digau "tebolet"». Aquells responien «sebolet». «Degolla'l!». E axín mataren tants mília dels contraris. Veus donchs ací com per la lengua coneixien de qual terra eren o de qual trib. (Schib 1984: 178).2

A continuació, esmenta una altra autoritat que no és sinó el passatge de l'evangeli de Mateu en el qual es descobreix la filiació de sant Pere per la seua parla. I tot seguit, l'aplicació moral. Més enllà de l'explicació literal de les cites bíbliques emprades, allò que interessa el predicador és extraure'n un significat moral pràctic:

2 Jt 12, 5-6. Es tracta de l'enfrontament entre els galaadites i els efraïmites, en el qual la pronúncia dialectal de la paraula que significa «espiga» és clau per a la identificació de l'enemic: «Els galaadites van ocupar els guals del Jordà, en direcció a Efraïm. I quan un efraïmita fugitiu els demanava que el deixaren passar, li preguntaven: -Ets d'Efraïm? Si contestava que no, li demanaven que diguera "xibòlet", però ell deia "sibòlet", perquè no sabia pronunciar-ho correctament. Aleshores l'agafaven i el degollaven vora els guals del Jordà. En aquella ocasió van morir quaranta-dos mil efraïmites». (BVI, AT: 344-345).

REVISTA VALENCIANA DE FILOLOGIA / I I I (20I9) p. 389-405

JOSEP E. RUBIO

El nus de la llengua en la xarxa dels sermons vicentins / 395 
Item, altra auctoritat $\left(\mathrm{Mt} ., 24^{\circ} \mathrm{ca}\right)$ : Quan vench a la Passió de Jesuchrist, que.ls juheus lo tenien pres en la casa de Pilat, ${ }^{3}$ e sent Pere anave detràs a veure què farien de son senyor, veus que aquells de la casa li digueren: «Tu ex illis es, nam loquela tua manifestum te facit». Axí dich de vosaltres, que en la lengua conexerà hom de qual terra sou.

Ara digau: quiny lenguatge és lo de paraís? Lo propheta David ó dirà (psalm "Quam dilecta»): «Beati qui habitant in domo tua, Domine; in secula seculorum laudabunt te». Donchs, la persona que no jure de Déu e va sovín a la església e hou misses devotament e sermons e ha bones paraules ab los proïsmes, vet que tu pots dir: «Haa! Tal persona de paraís és. Nam loquela tua manifestum te facit». Mas si és hun altre que no face sinó jurar de Déu e dels sants de paraís, e no cure molt de anar a la església, e si·y va, està's ab la lengua e.l queix, que no•s cure de fer oració; e si·u fa, pereosament e endormiscada, e parlarà aquí de fets mundanals, e puix baralle's ab d'altres, Oo! Tu li poràs dir a aquell: «Tu de infern és. Nam loquela tua manifestum te facit». (Schib 1984: 178-179).

L'ús de la llengua delata si un està entre els elets o entre els damnats. L'oposició «llenguatge del paradís» vs. «llenguatge de l'infern» s'articula a partir de l'oposició fonamental en el discurs moral pràctic del predicador «lloança» vs. «blasfèmia»; l'ús de la llengua per lloar Déu, però, va acompanyat d'altres gestos igualment indicadors de la pertinença a la comunitat dels salvats: anar sovint a missa $\mathrm{i}$ als sermons, tenir un capteniment correcte en la cerimònia, tenir bones paraules amb el prö̈sme, etc. Igualment, en la part contrària, qui jura i blasfema també parla de coses mundanes en la missa, no fa les oracions quan toca, es baralla amb el proïsme, etc.

La preocupació per un bon ús de la llengua és un dels temes centrals de la predicació dels ordes mendicants. Seria prolix centrar-nos ara en la importància que adquireix el llenguatge en la moral cristiana a partir del segle XIII:

3 Els evangelis coincideixen a fer de la casa del gran sacerdot Caifàs l'espai on va tenir lloc l'escena de les tres negacions, mentre Jesús era interrogat davant el sanedrí. Sols després d'aquest interrogatori va ser lliurat a Pilat. No és, ni de bon tros, l'únic cas que mostra que, en les reportacions, les cites bíbliques sovint estan alterades $\mathrm{o} a \mathrm{mb}$ referències errònies.

REVISTA VALENCIANA DE FILOLOGIA / I I I (20I9) p. 389-405

JOSEP E. RUBIO

El nus de la llengua en la xarxa dels sermons vicentins / 396 
remetem als estudis de Carla Casagrande i Silvana Vecchio, que estudien com en aquesta època els moralistes posen el focus en un nou pecat, el «pecat de la llengua», amb espècies diverses com la blasfèmia, la murmuració, l'adulació, el perjuri, etc. (Casagrande \& Vecchio 1991). La recurrència del tema en els sermons vicentins és una mostra de la pervivència d'aquesta preocupació. Sant Vicent aprofita l'oposició «llenguatge de paradís-llenguatge d'infern» per carregar precisament contra la blasfèmia, un dels cavalls de batalla de la seua particular croada per la reforma moral dels costums.

Així, al sermó «Steterunt a longe et levaverunt vocem» (Schib 1975: 229237) podem veure clarament reflectida la preocupació pel «pecat de la llengua», ja que tot ell hi és dedicat. El sermó és dividit en sis parts, corresponents als «sis punts de cants»; és a dir, a les sis notes de l'hexacord natural o escala de sis sons (ut, re, mi, fa, sol, la) que, en ser cantades, «eleven la veu» (com diu el tema bíblic) des del punt més greu al més agut.

La primera nota, la inferior, és ut, "e és veu infernal, blasfemant, que baix en infern ha veus de blasfèmies, que tot lo món blasfemen» (Schib 1975: 231). ${ }^{4}$ Ací apareix el nostre nus:

Veus acíla veu de infern, $u t$, veu blasfemant. E per ço podem treure de ací una bona doctrina moral; que ja sabets qui és ciutadà de infern, e sabets que són molts lenguatges en lo món, e en lo lenguatge coneix hom la persona de qual terra és. Axí com aquells que digueren a sent Pere, quan renegà Jesuchrist: «Vere galileus es $t u »$. E si vehets hun hom que parle lo ffrancés, direu: «Aquest hom francés és». Axí vosaltres, vehents que alguns reneguen Déu e blasfemen Déu, deveu tenir axí e dir: «Tu ex illis es», ço és, de infern, que tenen aquella veu infernal, un $u t$ blasfemant. Guardau-vos-en, que fort veu és e fort peccat és. E axí vosaltres, senyors de regidors de aquesta bona vila, feu-ne bon estatut e fort contra aquests traÿdors: passar-li hun clau per la lengua, que tingue del piquo de la barba fins al nas, e fer-lo estar en lo castell hun dia, e aprés bandegar-lo. (Schib 1975: 232).

4 Hem modificat el text editat per Gret Schib.

REVISTA VALENCIANA DE FILOLOGIA / I I I (20I9) p. 389-405 JOSEP E. RUBIO El nus de la llengua en la xarxa dels sermons vicentins / 397 
El blasfemador parla, doncs, la llengua de l'infern. I com que ha pecat amb l'òrgan de la llengua, el càstig que proposa sant Vicent és, precisament i en bona lògica, infligir un dany a la llengua passant-li un clau. La part inferior de la veu, la que correspon a l'infern, simbolitzada per la nota més greu de l'escala musical i, en el terreny moral, pel pecat de la blasfèmia, troba un referent material concret en l'òrgan de la llengua, en la part de l'anatomia que porta a terme el pecat en pronunciar els renecs i juraments que ofenen Déu. Ací no es parla de llengua en el sentit de 'loquela', de parla o d'idioma, sinó com a òrgan físic de la fonació. En aquest sentit, el terme entrarà en una oposició paral-lela a la que hem vist de «llenguatge celestial vs. llenguatge infernal», igualment operativa en el discurs moral dels sermons: l'oposició «llengua vs. cor».

La trobem enunciada en diversos llocs, en relació sempre amb el nus que estem tractant. Veiem així com el nus «loquela tua manifestum te facit» permet enllaçar diversos filats o passar d'un tema a un altre, tots connectats entre si a partir de la idea central, en aquest cas, del llenguatge com a marca identitària. Per exemple, al sermó de tema «Diliges proximum tuum sicut te ipsum» (Schib 1975: 187-197), el predicador introdueix la distinció entre llengua humana i llengua angèlica a partir de l'oposició «llengua-cor». Tot partint de la cita de sant Pau de la primera carta als Corintis «Si linguis hominum loquar et angelorum, charitatem autem non habeam, factus sum velut aes sonans, aut cymbalum tinniens» (1Co 13,1), explica: "Ací hi ha secret en ço que diu "si linguis hominum loquar et angelorum”, car l'om parle ab la lengua, troç de carn, e lo parlar de l'àngel és de cor, que los àngels se entenen solament per lo cor, que no·ls cal parlar, que axí ó entenen» (Schib 1975: 193).

El llenguatge angèlic, purament intel-lectual, un llenguatge mental «de cor a cor", s'oposa al llenguatge humà que necessita de l'òrgan de fonació de la llengua, «troç de carn». I és que, com repeteix sant Vicent en diversos llocs,

5 El tema de la «locutio angelica» es troba present en l'especulació sobre la naturalesa del llenguatge en l'escolàstica, vinculat al tema més ampli de l'existència d'un llenguatge interior. Sant Vicent hi fa referència en alguns dels seus sermons, sense entrar en el debat al voltant de la naturalesa d'aquest llenguatge interior. Per a un resum de les posicions de l'escolàstica sobre el llenguatge angèlic, vegeu Rosier-Catach (2017), amb un ampli repertori bibliogràfic a la nota 3.

REVISTA VALENCIANA DE FILOLOGIA / I I I (20I9) p. 389-405 JOSEP E. RUBIO

El nus de la llengua en la xarxa dels sermons vicentins / 398 
l'ofici de la llengua ben endreçada és «manifestar lo cor». Així ho expressa, per exemple, al sermó dedicat a les sis notes musicals que hem vist abans, en tractar de la tercera nota, «mi», «veu mundanal»: «quant hom compra e ven, estan en fira, mil mília veus haurà aquí falsies» (Schib 1975: 234). Molts comerciants enganyen amb la llengua: menteixen o juren per guanyar diners. ${ }^{6}$ No usen correctament, doncs, de «l'ofici de la llengua»:

Qual offici és de la lengua? Manifestar lo cor, quia «ex abundantia cordis os loquitur» $\left(\mathrm{Mt}\right.$., XII $\left.{ }^{\circ} \mathrm{ca}^{\circ}\right)$. Hun hom que sie superbiós e van, tots temps parlarà de honors; lo avariciós, de riquees: senyal és que és avariciós; lo luxuriós parle de luxúria: senyal és que és luxuriós, etc. Ara escolta: si offici és de la lengua manifestar lo cor, e donchs, axí com la ceguetat està mal en l'uyll, axí està mal la falsia o la jura en la lengua. Mal punt hi anau ab aquesta veu mundanal. (Schib 1975: 234).

L'oposició «cor-llengua» porta també cap al tractament de la blasfèmia, igual que l'oposició «llenguatge infernal-llenguatge celestial». Totes dues oposicions estan estretament unides pel nus que estem tractant, i vinculades a sengles cotextos que n'afavoreixen l'aparició (les cites bíbliques de sant Mateu, «loquela tua manifestum te facit», i de sant Lluc, «ex abundantia cordis os loquitur»). D'acord amb la glossa bíblica de l'evangeli de sant Mateu, Sant Pere, en negar Jesús, va cometre pecat de blasfèmia, ja que va renegar de Déu. Segons l'oposició «llengua-cor», la primera no va manifestar el missatge del segon. Diu sant Vicent que «ell no·l negà de cor, mas de lengua, e per paor de morir». Aquesta afirmació es troba en el sermó hagiogràfic dedicat a sant Pere, encapçalat pel tema «Beatus es Simon Bariona» (Sanchis Sivera 1934: 45-54). Aquest pecat comés per sant Pere en negar Jesús fou gravíssim, segons el predicador, i és equivalent al pecat de blasfèmia que cometen els qui reneguen de Déu o l'«especegen»:

6 Sobre l'estereotip moral de l'ofici de mercader, que sofreix una evolució cap a una progressiva acceptació social d'aquests en l'obra dels moralistes com Eiximenis o sant Vicent, vegeu Puchades i Bataller (1999: 122-128).

REVISTA VALENCIANA DE FILOLOGIA / I I I (20I9) p. 389-405 JOSEP E. RUBIO El nus de la llengua en la xarxa dels sermons vicentins / 399 
Ara, donchs, pensa tu, home, quan jugues als daus, e lo punt fa contra tu, ab malícia dius: «Oo, mal grat», o «a despit», o «yo renech», etc. E és major peccat una vegada de tu, que deu de sent Pere. Aprés, per entrar en una casa: «Entrat vós». "No faré; ans vós»; abans que no entraran: "yo renech de Déu, si vós no entrau primer». Sobre hun beure, hoc; sobre hun entrar de una església, allí renegaran, e·l esquarteraran. Los juheus cortesament ne usaren, que no li trenquaren degun os; mas, los christians esquarterar, lacerar pels budells, pel cul. ¡Oo, meravella és, quan foch no devalle del cel, e que·ls creme a tals renegadors e juradors e hoïdors e regidors de les comunitats! (Sanchis Sivera 1934: 50).

La llengua com a instrument de la blasfèmia és l'òrgan amb el qual, mitjançant un llenguatge diabolical, els pecadors ataquen Déu, amb la intenció d'esquarterar-lo. De l'oposició «llenguatge celestial-llenguatge infernal» hem passat a l'oposició paral-lela "cor-llengua». Aquesta llengua, que ha de ser castigada (amb un càstig físic, com hem vist: essent travessada per un clau), formarà part, en altres sermons, d'una semblança que permetrà posar en relació el nus del llenguatge com a manifestació de la identitat del pecador amb altres. Ens referim a una semblança de tipus militar que connecta amb el «loquela tua manifestum te facit» a partir del tema compartit de la blasfèmia. La llengua és una peça clau en la comissió del pecat de blasfèmia. És l'arma amb què el pecador ataca Déu, que es troba dalt, en el castell, protegit per les muralles inexpugnables. El blasfem, no obstant això, dispara el dard, el projectil de la llengua cada cop que blasfema. La semblança posa en relació les parts d'una ballesta amb la boca, instrument del pecat:

Susaxí és quan les gens blasfemen: Déus tramet mort corporal e mal temps. Ara, voleu la rahó? Si són uns qui combaten hun castell ab sagetes, los de dalt com se deffensen? Ab quanteres. Susaxí fa Déus: lo qui jure combat a Déu, qui està dalt en lo castell. E com? Ab ballesta. Vet la boqua, lo labi davall és la corda, lo dessús és l'arc, la lengua lo virató: «pru, tpruu». E Jesuchrist ab quanteres, ab pedres. Tot lo món se pedrege, ara que no·u solie fer, mas ara port e plana. (Schib 1977: 211).

REVISTA VALENCIANA DE FILOLOGIA / I I I (20I9) p. 389-405

JOSEP E. RUBIO

El nus de la llengua en la xarxa dels sermons vicentins / 400 
La mateixa semblança trobem en un altre sermó (Sanchis Sivera 1932: 66), on també es parla de "fer la guerra» contra Déu. La llengua representa l'arma, que bé és l'espasa ("Quan tu dius "Pel cap de Déu!", ara li lleves lo cap ab la spasa de la llengua»), bé, de nou, el projectil de la ballesta («Aprés, quan dius: "Yo renech", ara li tramets hun passador, car la boqua axí és com la ballesta de dos fusts: vet, lo labi d'amunt és l'arch voltant, e lo labi d'avall és la corda; e.l passador que li tramets és la lengua, qui fa: "Bruu”»).

I encara, aquesta semblança de la ballesta ens porta a una altra de contrària, com a mostra de la polivalència dels recursos emprats en la predicació: la ballesta, en un dels sermons de Quaresma (XXII, de tema «Fortis armatus custodit atrium suum»), esdevé semblança de la compassió, que ha d'impulsar el cristià a fer almoina. El virató o projectil és doncs, en aquest cas, les bones obres que el creient dispara contra el dimoni en la batalla general que tota la cristiandat té contra l'enemic en el temps de Quaresma.7

Cada almoina e cada obra de misericòrdia, és virató que fer al diable, e així, en est sagrat temps, los qui fan almoines han ofici de ballesters. La ballesta té lo arc tort e lo arbrer dret, e corda tibant: lo arbrer és la intenció dreta. Guarda't que sia dreta la intenció a Déu: «Te faciente eleemosynam, nesciat sinistra quid faciat dextera» (Mt, 6, 3). Dreta sia la intenció: ordena la tua intenció dreta, que vaja dret, així com lo ballester que atenta primer. Ítem, lo arc tort és lo cos, que es deu inclinar a haver compassió de son prö̈sme, pensant en les prosperitats que és, e en les misèries que és lo pobre. E l'almoina no solament requir intenció dreta, mas haver compassió: açò és l'arc tort que s'inclina [...]. La corda tibant hi és mester, ço és, lo manament de Déu [...]. E així, si haveu estes tres coses, metets-hi lo virató, e darà gran colp al diable, ab aquests passadors encebats e encuixats. (Sanchis Guarner 1973: 181).

Tenim doncs una mateixa semblança interpretada en sentits radicalment contraris. En realitat, hem passat del nostre nus de la llengua, a través de la

7 Sobre les al·legories de tipus militar emprades per sant Vicent, amb una anàlisi d'aquest sermó de Quaresma, vegeu Ysern 2019.

REVISTA VALENCIANA DE FILOLOGIA / I I I (20I9) p. 389-405

JOSEP E. RUBIO

El nus de la llengua en la xarxa dels sermons vicentins / 40I 
semblança de la ballesta, a un altre de diferent. La llengua com a òrgan del pecat de la blasfèmia es pot incorporar a la semblança militar de la ballesta; la qual, al seu torn, en altres sermons, serveix per mostrar la virtut de la misericòrdia: ens movem, ací, en un terreny totalment diferent. La presència comuna, però, d'una mateixa semblança, els connecta tots dos gràcies a la facilitat amb què, a través dels nusos mòbils, ens podem traslladar en la xarxa que posa en relació temes, cites bíbliques, semblances, exemples, etc., més enllà d'un sermó aillat: es tracta d'una xarxa que uneix tots els sermons.

Així doncs, veiem com a partir d'un mateix nus ens movem d'un a un altre sermó, i passem d'uns temes a uns altres connectats a través de semblances polivalents. Tots aquests recursos són peces que construeixen la xarxa del sermó i que, en viatjar dels uns als altres, configuren un espai hipertextual, una xarxa multidimensional. El següent esquema podria ser una mena de mapa o de representació gràfica del nostre nus, «la llengua com a signe identificador».

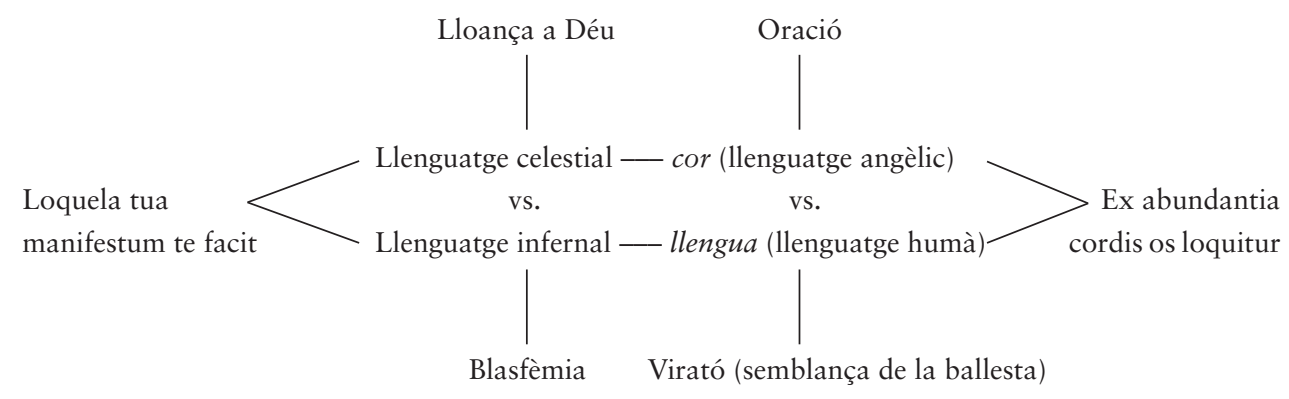

$\mathrm{Al}$ centre, les dues oposicions que l'articulen: la llengua com a manifestació de l'origen del parlant deriva en l'oposició «llenguatge celestial vs. llenguatge infernal», vinculada, a través dels «òrgans» que permeten la comunicació, amb l'oposició «cor vs. llengua» (entenent, en aquest cas, llengua en el sentit d'òrgan material de la fonació' o, com diu sant Vicent, «tros de carn»). En el primer cas, el cor, instrument de la «locutio angelica», connecta directament amb el «llenguatge celestial» en sentit estricte, mentre que la llengua és l'instrument del «llenguatge humà». Aquest darrer pot manifestar, no obstant l'oposició amb el llenguatge an-

REVISTA VALENCIANA DE FILOLOGIA / I I I (20I9) p. 389-405 JOSEP E. RUBIO

El nus de la llengua en la xarxa dels sermons vicentins / 402 
gèlic, que el parlant és habitant del paradís si la llengua manifesta convenientment «l'abundància del cor»: si no enganya i manifesta cap a fora el que dicta el cor.

Aquesta doble oposició és doncs el nucli del nus, format per la unió de dos fils o cotextos: les dues cites bíbliques que l'emmarquen. Cada cop que un segueix aquests fils, va a parar al nus de la llengua com a signe identificador del parlant. Des del nus, articulat així en una doble oposició, podem passar a altres fils, i amb ells a altres temes, a altres nusos. El llenguatge infernal es relaciona sempre amb la blasfèmia. El celestial, amb la lloança a Déu. Tots dos temes, però, van acompanyats d'altres referències a comportaments morals que se'n deriven: capteniment en la missa, tracte amb el pròxim, etc. De cada cap, «blasfèmia» o «lloança a Déu», podem estirar i arribar així a altres temes en altres sermons. D’altra banda, també en l'altra oposició, el llenguatge angèlic conforma un altre cap de fil a partir del nus i, si l'estirem, arribarem a altres temes: per exemple, el de l'oració. Sovint, en tractar les formes d'oració, sant Vicent introdueix la qüestió dels dos llenguatges, l'humà i l'angèlic; en concret, en referir-se a l'oració que es fa posant els dos genolls en terra. Així, al sermó de tema «Sublevatis Iesus occulis in celum, dixit», tenim:

La .III'. manera és ficar los genolls en terra [...]. «Viuo ego, dicit Dominus, mibi flectetur omne genu, et omnis lingua confiteatur» (Ad Ro., $\left.. X I I I^{\circ} . c a^{\circ}\right)$. Per què diu «omnis lingua»? La lengua del cors e de la ànima. E la ànima ha lengua? Hoc, la manifestació de la pensa: «Linguis hominum loquar et angelorum» [.I. Cor., $13^{\circ} \mathrm{ca}{ }^{\circ}$, ço és, la actual consideració que quan fareu oració, primo ficau abdós los genolls, e fent la oració ab la pensa, ferm pensar que estau als peus de Jesuchrist, et omnis lingua confiteatur Deo. (Sanchis Sivera 1932: 25-26). ${ }^{8}$

8 Als sermons de Quaresma en tenim una altra versió; en aquest cas, la referència a la llengua dels àngels és més explícita: bo i partint de les mateixes cites bíbliques, no es parla de «llengua del cors e de l'ànima», sinó de «llengües de hòmens e de àngels»: «la de hòmens és la llengua peça de carn; los àngels, movent lo propi enteniment, parlen sens parlar» (Sanchis Guarner 1973b: 131). En qualsevol cas, també ací la referència es relaciona directament amb el tema de l'oració, que no és, en definitiva, més que la forma de «parlar amb Déu». Una oració que ha d'anar acompanyada d'uns gestos, com ficar els dos genolls a terra, entre altres que explicita el predicador. Veiem així la rendibilitat del nus mòbil de la llengua, que permet introduir diversos temes en diversos sermons.

REVISTA VALENCIANA DE FILOLOGIA / I I I (20I9) p. 389-405

JOSEP E. RUBIO

El nus de la llengua en la xarxa dels sermons vicentins / 403 
La llengua com a òrgan físic de la parla humana pot també relacionar-se amb la blasfèmia en tant que instrument d'aquesta. La idea és desenvolupada a través d'una semblança que, de manera precisa, relaciona les parts d'una ballesta amb la boca del blasfem, essent la llengua el «virató» o projectil llançat contra Déu. Podem eixir d'aquest nus i passar a un altre a partir d'aquesta semblança, ja que la mateixa ballesta pot significar, en un altre context, un tema totalment diferent: la misericòrdia i la caritat envers els necessitats. De cada un dels fils que convergeixen en el nus dibuixat podem així passar a d'altres de forma directa, i d'aquests a molts d'altres, en un viatge continu que ens portarà per tota la predicació vicentina organitzada a partir de temes específics que, com a peces mòbils, articulen el gros de les seues preocupacions com a predicador.

REVISTA VALENCIANA DE FILOLOGIA / I I I (20I9) p. 389-405 


\section{Bibliografia}

Abreviatures:

BVI: Bíblia valenciana. Traducció interconfessional, Castelló, Saó, 1996 (AT: Antic Testament; NT: Nou Testament).

DCVB: Alcover-Moll, Diccionari català-valencià-balear <http://dcvb.iecat.net/>.

\section{ESTUDIS I EDICIONS:}

Aquino, SANT Tomàs D’ (1951) Super Evangelium S. Matthaei lectura, Torí, Marietti (http:// www.corpusthomisticum.org/cml26.html\#87408).

Casagrande, C.; Vecchio, S. (1991) Les péchés de la langue, París, Cerf.

Ferrando, A. (1997) «Vicent Ferrer (1350-1419), predicador políglota de l'Europa occidental», dins Paradigmes de la història, I. Actes del Congrés "Sant Vicent Ferrer i el seu temps» (València, 13-16 maig, 1996), València, Saó, pp. 71-95.

Puchades i Bataller, R. J. (1999) Als ulls de Déu, als ulls dels homes. Estereotips morals i percepció social d'algunes figures professionals en la societat medieval valenciana, València, Departament d'Història de l'Antiguitat i de la Cultura Escrita, U. D. Paleografia, Universitat de València.

Rosier-Catach, I. (2017) «La locutio angelica dans la scolastique médiévale», Annuaire de l'École pratique des hautes études (EPHE), Section des sciences religieuses 124, pp. 277 282 (http://asr.revues.org/1632).

Rubio, J. E. (2007) «Estratègies divulgatives i pedagògiques en els sermons vicentins: de la filosofia a la moral», dins El fuego y la palabra. San Vicente Ferrer en el 550 aniversario de su canonización, València, Generalitat Valenciana.

SAnchis Guarner, M. (I973) Sermons de Quaresma I, sant Vicent Ferrer, València, Clàssics Albatros, 2 vols.

- (I973b) Sermons de Quaresma II, sant Vicent Ferrer, València, Clàssics Albatros, 2 vols. Sanchis Sivera, J. (ed.) (1932) Sermons I, sant Vicent Ferrer, Barcelona, Barcino, 6 vols.

- (1934) Sermons II, sant Vicent Ferrer, Barcelona, Barcino, 6 vols.

Sснів, G. (1975) Sermons III, sant Vicent Ferrer, Barcelona, Barcino, 6 vols.

- (I977) Sermons IV, sant Vicent Ferrer, Barcelona, Barcino, 6 vols.

- (1984) Sermons V, sant Vicent Ferrer, Barcelona, Barcino, 6 vols.

Ysern, J. (2015) Como una red. Sermones de Vicent Ferrer, València, Universitat de València.

- (2017) «A propòsit dels nusos mòbils en la construcció dels sermons vicentins», Revista de Filología Románica 34 (1), pp. 33-62 (<http://dx.doi.org/10.5209/RFRM.55628>).

- (2019) «Armes, armadures i batalles al-legòriques en els sermons de Vicent Ferrer», Anuario de Estudios Medievales 49 (1), pp. 287-312 (<https://doi.org/10.3989/ aem.2019.49.1.11>).

REVISTA VALENCIANA DE FILOLOGIA / I I I (20I9) p. 389-405

JOSEP E. RUBIO

El nus de la llengua en la xarxa dels sermons vicentins / 405 


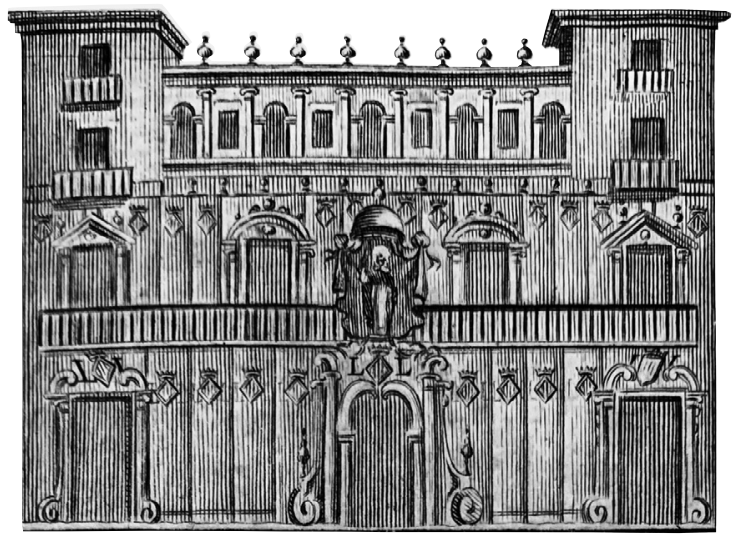

